\title{
Frontalis sling procedure for ocular myasthenia gravis
}

This article was published in the following Dove Press journal:

Clinical Ophthalmology

II April 2012

Number of times this article has been viewed

\author{
Shinichi Asamura' \\ Hirohiko Kakizaki² \\ Mitsuhiro Enjyo' \\ Takahiro Hashimoto' \\ Noritaka Isogai' \\ 'Department of Plastic and \\ Reconstructive Surgery, Kinki \\ University School of Medicine, \\ Osakasayama, Osaka, Japan; \\ ${ }^{2}$ Department of Ophthalmology, \\ Aichi Medical University, Nagakute, \\ Aichi Japan
}

Correspondence: Shinichi Asamura Department of Plastic and Reconstructive Surgery, Kinki University School of Medicine, Osakasayama, Osaka, Japan

$\mathrm{Tel}+8 \mathrm{I} 72366022$ I

Fax +81723677517

Email asamura@med.kindai.ac.jp
Abstract: A 39-year-old woman was diagnosed with myasthenia gravis when she was 8 years old. Although many treatments - such as cholinesterase inhibitors and steroids - had been given to the patient, her condition did not improve sufficiently. As she demonstrated bilateral $3 \mathrm{~mm}$ levator function without any eye movement disturbances, bilateral frontalis sling procedures were performed with an autologous fascia lata. One year after the operation, the operated upper eyelids showed symmetrically appropriate heights with good functional outcome. A sling procedure with an autologous fascia lata was suitable for correcting poor levator function of an ocular myasthenia gravis case.

Keywords: ocular myasthenia gravis, ptosis, frontalis sling

\section{Introduction}

Myasthenia gravis (MG), an autoimmune disease, impedes the postsynaptic acetylcholine receptors at the neuromuscular junction. ${ }^{1}$ Ocular $\mathrm{MG}$ is a representative manifestation of this entity in which blepharoptosis and/or eye movement disturbances are often encountered. ${ }^{2}$ In general, up to $85 \%$ of all myasthenic patients show the anticholinesterase receptor antibody in serum, but only about $50 \%$ of patients demonstrate ocular muscle weakness. ${ }^{3}$ Although cholinesterase inhibitors with or without steroids are commonly used as a treatment modality, they are, occasionally, less effective for ocular symptoms. ${ }^{4}$ In such a case, especially for ptosis without any eye movement disorders, ptosis surgery is often performed. This paper presents an ocular MG case with eyelid dysfunction, in which cholinesterase inhibitors and steroids did not work sufficiently, but surgical treatment successfully improved the symptom.

\section{Case report}

A 39-year-old woman was diagnosed with MG when she was 8 years old. With a positive edrophonium test and detectable serum acetylcholine receptor antibody, the diagnosis of ocular MG was confirmed in addition to the unresponsiveness to treatment with pyridostigmine and steroids at 31 years of age. Despite long-term treatment with steroids, she had difficulty opening both eyes, which caused stiff shoulders and headaches. She was then referred to the authors' clinic for possible surgical management.

As she showed bilateral $3 \mathrm{~mm}$ levator function (Figure 1A) without any eye movement disturbances, bilateral frontalis sling procedures were performed with an autologous fascia lata. The skin incision was made $6 \mathrm{~mm}$ from the eyelid margin, 

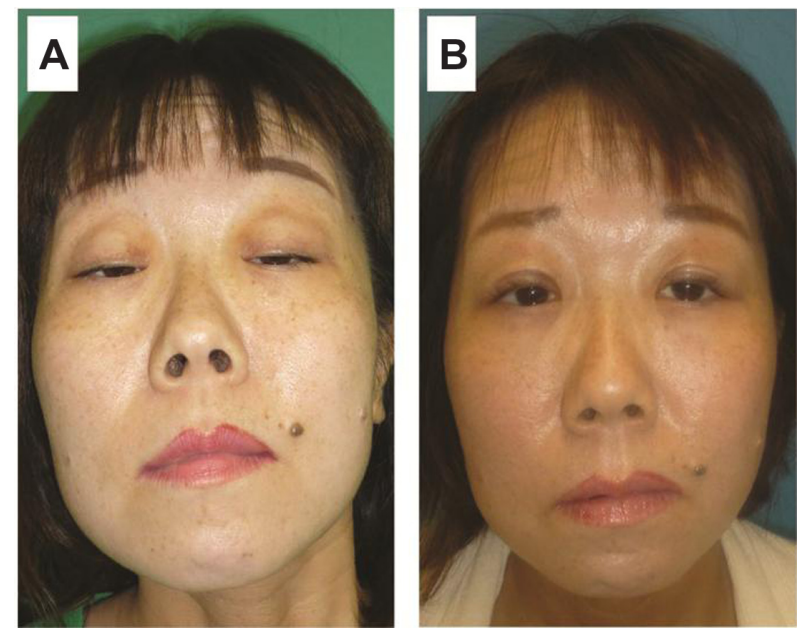

Figure I (A) Preoperative view of the patient with ptosis shows that she has a prominent wrinkle in her forehead and sticks out her chin when she tries to open her eyes. (B) Postoperative view shows that the eyelids are symmetrical and in the appropriate position I year after the operation.

and the central area of the upper brow margin was also incised (Figure 2A). A tunnel was made from the brow incision through the suborbicularis oculi layer, and reached the pretarsal area. The branched fascia lata was sutured with 6-0 nylon (Sigma, Tokyo, Japan) on the tarsal plate and then the upper eyelid curvature was confirmed by pulling the fascia through the suborbicularis tunnel (Figure 2B). After the upper eyelid height was adjusted appropriately with a trial suture at the brow incision, the fascia was fixed at the subcutaneous tissue of the brow.

One year after the operation, the upper eyelids showed symmetrically appropriate heights (Figure 1B). The patient did not demonstrate exposure keratitis, wound infection, lagophthalmos, or ptosis in the 6 months following the operation.

\section{Discussion}

The frontalis sling surgery for ptosis by ocular MG accomplished functionally and cosmetically good outcomes.
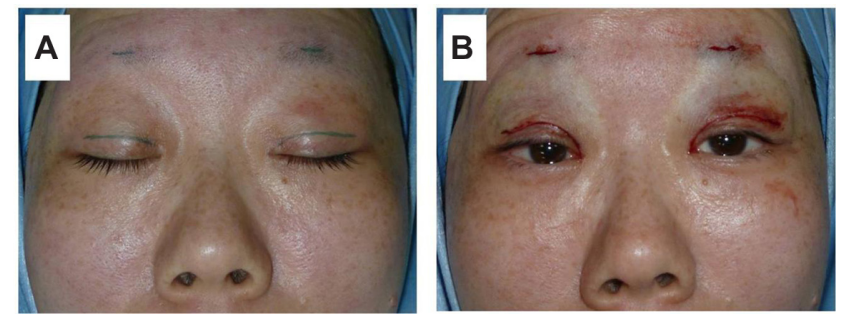

Figure 2 (A) Marking of the incisions before the procedure. The skin incision was made $6 \mathrm{~mm}$ from the eyelids margin, and the central area of the upper brow margin was also incised. (B) A view of the skin incisions before closure. With autologous fascia lata, bilateral frontalis slings were performed.
As the levator function of the patient was bilaterally $3 \mathrm{~mm}$, the frontalis sling technique was chosen. In general, ptosis with less than $4 \mathrm{~mm}$ levator function needs a sling procedure, ${ }^{5}$ but with more levator function, levator advancement surgery is applied. ${ }^{6}$ As an excessive advancement of levator often leads to an eyelid-eyeball dissociation, causing dry eyes, a sling procedure should be used in such a case. In the past, numerous materials have been used for slings like silicone rods, GORE-TEX ${ }^{\circledR}$, and autologous tissue graft. ${ }^{5,7-9}$ The autologous graft from fascia lata was chosen rather than the artificial material in terms of its histocompatibility.

Although the patient did not show any eye movement disturbances, MG patients often show eye movement disturbances simultaneously with ptosis. ${ }^{10}$ Bilateral ptosis surgery should be avoided in such a case to prevent postoperative diplopia. In this situation, ptosis surgery should only be applied to one side.

Many treatment modalities had been given to the patient, but her condition did not show definite improvement. Generally in MG, anticholinesterases (cholinesterase inhibitors) have limited efficacy. Although steroids are of great short-term benefit in most patients with ocular MG, the side effects associated with steroids may prevent long-term use. ${ }^{10}$ Therapeutic effect of thymectomy is controversial for ocular MG. Therefore, a patient refractory to any medical treatments is a good candidate for ptosis surgery.

In conclusion, this paper reports an ocular MG case with eyelid dysfunction, in which cholinesterase inhibitors and steroids did not work sufficiently, but surgical treatment successfully improved the symptom. A sling procedure with an autologous fascia was suitable for correcting poor levator function of an ocular MG case.

\section{Disclosure}

The authors report no conflicts of interest in this work.

\section{References}

1. Sghirlanzoni A, Peluchetti D, Mantegazza R, Fiacchino F, Cornelio F. Myasthenia gravis: prolonged treatment with steroids. Neurology. 1984;34(2):170-174.

2. Elrod RD, Weinberg DA. Ocular myasthenia gravis. Ophthalmol Clin North Am. 2004;17(3):275-309.

3. Sommer N, Sigg B, Melms A, et al. Ocular myasthenia gravis: response to long-term immunosuppressive treatment. J Neurol Neurosurg Psychiatry. 1997;62(2):156-162.

4. Roh HS, Lee SY, Yoon JS. Comparison of clinical manifestations between patients with ocular myasthenia gravis and generalized myasthenia gravis. Korean J Ophthamol. 2011;25(1):1-7.

5. Philandrianos C, Galinier P, Salazard B, Bardot J, Magalon G. Congenital ptosis: long-term outcome of frontalis suspension using autogenous temporal fascia or fascia lata in children. J Plast Reconstr Aesthet Surg. 2010;63(5):782-786. 
6. Brandley EA, Bartley GB, Chapman KL, Waller RR. Surgical correction of blepharoptosis in patients with myasthenia gravis. Ophthal Plast Reconstr Surg. 2001;17(2):103-110.

7. Carter SR, Meecham WJ, Seiff SR. Silicone frontalis slings for the correction of blepharoptosis: indications and efficacy. Ophthalmology. 1996;103(4):623-630.

8. Yu CC, Chen SG, Chen TM. Frontalis slings with palmaris tendon as an adjuvant treatment for myasthenic blepharoptosis: a case report. Ann Plast Surg. 2007;58(5):577-579.
9. Wasserman BN, Sprunger DT, Helveston EM. Comparison of materials used in frontalis suspension. Arch Ophthalmol. 2001;119(5): 687-691.

10. Kupersmith MJ, Latkany R, Homel P. Development of generalized disease at 2 years in patients with ocular myasthenia gravis. Arch Neurol. 2003;60(2):243-248.
Clinical Ophthalmology

\section{Publish your work in this journal}

Clinical Ophthalmology is an international, peer-reviewed journal covering all subspecialties within ophthalmology. Key topics include: Optometry; Visual science; Pharmacology and drug therapy in eye diseases; Basic Sciences; Primary and Secondary eye care; Patien Safety and Quality of Care Improvements. This journal is indexed on

Submit your manuscript here: http://www.dovepress.com/clinical-ophthalmology-journal

\section{Dovepress}

PubMed Central and CAS, and is the official journal of The Society of Clinical Ophthalmology (SCO). The manuscript management system is completely online and includes a very quick and fair peer-review system, which is all easy to use. Visit http://www.dovepress.com/ testimonials.php to read real quotes from published authors. 